\title{
Begrenzing in de forensische psychiatrie
}

\author{
R. Vriesema ${ }^{*}$
}

\section{Inleiding}

In de nieuwe roman van Jutta Richter De oorsprong van alles kijkt Adam terug op zijn leven. Verbitterd vraagt hij zich af waar de liefde is gebleven. Eva was de vervulling van al zijn wensen - en het begin van het einde. Want ze neemt geen genoegen met wat de Heer hun toestaat, wil almaar meer. En Adam is te zwak om haar tegen te houden. Ze moeten de tuin verlaten, omdat Adam de vriendschap met de Heer heeft verloochend. Het paar staat in de kou. Maar dan komt het kind, Kaïn, en dat is een geluk. Een breekbaar geluk, want Kaïn lijkt op Eva, ook hij kent geen grenzen. Pas als Abel er is, de tweede zoon, die naar Adam aardt, lijkt alles volmaakt. Alleen de Heer weet dat er met de liefde van de vader voor dit ene kind een nieuwe tragedie begint. De zondeval mondt uit in een moord en onder een ontroostbare maan praat Adam, de oude, met een wijze poes. Die poes speelt in het boek een belangrijke rol. Soms voert ze zelf het woord. Of de verteller kiest haar perspectief en dan denkt de poes dit: 'Zo zijn de mensen immers? Naderhand zeggen ze altijd dat ze het niet wilden.

Maar eerst doen ze precies wat ze niet willen en geen kat ter wereld zal dat ooit kunnen begrijpen...'

Voor de forensische psychiater is het herkennen, beoordelen en hanteren van grensoverschrijdend gedrag aan de orde van de dag. Aan de hand van zijn kennis hierover doet de forensisch psychiater uitspraken over toerekeningsvatbaarheid, recidivegevaar en behandelbaarheid. Of het nu gaat om een levensdelict, diefstal, mishandeling of vernieling, telkens is de centrale vraag hoe het zover heeft kunnen komen en of recidive is te voorkomen.

Roelof Vriesema is werkzaam als psychiater-psychoanalyticus 
We worden geconfronteerd met psychiatrische ziektes, verslavingen of persoonlijkheidsstoornissen en vaak is er sprake van een combinatie van factoren. Anders geformuleerd: op welke vlakken bestond er ten tijde van het telastegelegde begrenzingproblematiek bij de justitiabele en is deze problematiek nog veranderbaar dan wel moet begrenzing van buitenaf worden aangebracht om herhaling zo goed mogelijk te voorkomen.

In zijn rol van psychiater in de penitentiaire inrichting is begrenzing het leidmotief in de bejegening van gedetineerden en een voorwaarde voor een goede samenwerking met andere disciplines. Bewerkstelliging van besef van noodzakelijke begrenzing is een belangrijk doel voor onszelf en de justitiabelen. Met andere woorden: we moeten er achter komen wat reëel en haalbaar is bij onszelf en bij de ander. En we moeten kunnen erkennen dat we wezenlijk van elkaar kunnen verschillen. Het besef van verschil tussen mijn en dijn kan echter door verschillende oorzaken ontbreken of verstoord zijn geraakt. In de penitentiaire inrichting worden gedetineerden met psychische problematiek besproken in het psycho-medisch overleg, waarbij het begrenzingaspect over het te voeren beleid telkens aan de orde komt. Bevindt iemand zich op de juiste afdeling, casu quo in de juiste setting, en is hij verder in staat zich zelfstandig te handhaven, en zo niet, welke hulp kunnen we hem dan bieden en wie kan dat het beste doen. Ik noem een aantal voorbeelden:

\section{Voorbeelden van begrenzingsproblematiek}

Meneer A. is een 32-jarige man van Marokkaans/Spaanse afkomst, die op jonge leeftijd alleen is komen te staan en een zwervend bestaan leidt door Europa. Er is sprake van harddrugsverslaving en verwervingscriminaliteit. Tijdens zijn voorlopige hechtenis vraag hij plotseling om plaatsing in de isoleercel, omdat hij zich gespannen voelt. Dit verzoek wordt gehonoreerd. Hij zit nog niet in de isoleercel, of hij beukt met zijn hoofd tegen de muren en ook voor het opgetrommelde bijstandsteam is hij onhandelbaar. Hij krijgt van de inrichtingsarts hoofdbescherming en wordt gefixeerd. Hij weigert elke medewerking en hij wordt aangemeld voor de landelijke afzonderingsafdeling, die meer is toegerust voor dit soort excessen. Betrokkene is niet psychotisch, maar door drugsgebruik neigt hij periodiek tot ernstige zelfbeschadiging en agressiviteit, met als complicerende factoren: HIV-positief in combinatie met hepatitus-C. 
Een 36-jarige man B. schiet vanuit zijn flat tweemaal met een luchtbuks op zijn buurman en slaat hem bij een andere ontmoeting op diens neus. De buurman zegt de dader in feite nauwelijks te kennen, want als buren hebben ze geen contact. De verdachte is een paranoïd schizofrene man, die eerder is veroordeeld tot één jaar gedwongen behandeling in een psychiatrisch ziekenhuis wegens het gooien van een bijl in de richting van twee jongens, die hem zouden hebben gepest. Tijdens het onderzoeksgesprek zien we een atletisch gebouwde, goed getrainde man, die op een gedreven manier vertelt, hoe hard hij kan werken, hoe veel hij kan sporten en dat hij een echte man is. Aanvankelijk krijg je de indruk te maken te hebben met iemand die overspannen is geraakt in het werk. Maar als ik probeer met hem over zijn buurman te praten, komt er een ander verhaal: "De buurman zegt dat ik een kaboutertje ben en hij heeft mij samen met die andere "vaginisten" verkracht. Dat blijkt ook wel, want ik zat onder het bloed toen ik was aangehouden. Zij denken dat zij de echte mannen zijn, maar wij zijn de echte mannen. Ik ben geen homo en hij moet van me afblijven". Als ik verdachte vraag of hijzelf aangifte heeft gedaan van deze verkrachting, zegt hij daar geen tijd voor te hebben gehad. Bij verder doorvragen blijkt, dat hij in de auto altijd een honkbalknuppel bij zich heeft voor het geval de buurman hem weer zal lastigvallen en weer iets van hem wil.

Het advies aan de officier van justitie is om een multidisciplinair onderzoek te laten verrichten. In dit onderzoek wordt de diagnose paranoïde schizofrenie bevestigd en de rapporteurs zijn van mening, dat betrokkene volledig ontoerekeningsvatbaar is en maximaal één jaar verplicht behandeld zou moeten worden in een psychiatrische kliniek. Een probleem daarbij is, dat hij psychofarmaca zou weigeren. Als de zaak op de zitting komt, oppert de advocaat dat zijn cliënt wel wil verhuizen om zodoende het probleem op te lossen, terwijl de officier vraagt, waarom er geen TBS is geadviseerd.

Een 50-jarige man C., heeft zijn huis in brand gestoken. In het Pro Justitiaonderzoek komt hij naar voren als een bovengemiddeld intelligente man, die na een periode van mentale en fysieke overbelasting, uitgeput en depressief is geraakt en tenslotte in een panische en depressieve stemming brand heeft gesticht in zijn zelfgebouwde woning: hij raakte overspoeld door voor hem niet te hanteren gevoelens van hopeloze uitzichtloosheid en dit kwam tot acting out. Betrokkene is als middelste en enige zoon van drie kinderen beschermd opgegroeid en kreeg onvoorwaardelijke steun van zijn vader. 
Gevoelens van onzekerheid overdekte hij met het tegendeel; hij ging altijd voor de overwinning en kon slecht tegen zijn verlies. Hij doorliep de HTSbouwkunde zonder problemen en had verschillende relaties met meisjes. Op zijn dertigste verbrak hij vrij plotseling de relatie met zijn toenmalige vriendin: "Om er maar vanaf te zijn". Kort daarop raakte hij depressief en had gedurende één jaar gesprekken met een hulpverlener. Betrokkene werkte als leidinggevende bij gemeentelijke woningbouwcorporaties, maar hij wilde voor zichzelf beginnen en na een aanvankelijke combinatie van beide, nam hij ontslag en werd zelfstandig ondernemer.

Hij vond het leuk om te verbouwen en te klussen en van zijn hobby heeft hij zijn werk gemaakt. Hij bouwde enkele huizen en tenslotte ook een huis voor zichzelf. Er ontstonden problemen met de gemeente over de aanvoerweg van zijn huidige huis. Betrokkene schakelde de krant en andere media in, maar dit leidde tot niets. Hij besloot het huis te koop aan te bieden en alras was er iemand geïnteresseerd, maar na een bouwtechnisch onderzoek, zag deze af van de koop. Betrokkene had al zijn geld in de woning gestoken en moest nog eens extra geld lenen bij een zwager om de dakconstructie te herzien. Betrokkene zegt, voor het tenlastegelegde nog niet beseft te hebben dat hij ook problemen zou krijgen met de andere huizen die hij had gebouwd, maar hij raakte wel toenemend depressief, teruggetrokken en gevoelloos en hij heeft in een soort van gevoelloze, depressieve actie het huis in brand gestoken. Hij heeft dit direct aan zijn vrouw verteld, die buiten wandelde en hij besefte direct, dat hij een stomme fout had begaan: "Het was een soort vlucht, alsof ik daarna opnieuw kon beginnen. Maar dat slaat nergens op". Op het politiebureau zou hij suïcidaal zijn geweest en ook enkele dagen voor het eerste onderzoeksgesprek, zag hij het allemaal niet meer zitten en had gedachten zich voor de trein te werpen. Een week later doet hij een forse suïcidepoging en snijdt zich in zijn polsen. Vervolgens verblijft hij op een gesloten psychiatrische afdeling en begint met het gebruik van antidepressiva en rustgevende medicijnen, die hij tot dan toe had geweigerd.

In de persoonlijkheidsstructuur zijn er aanwijzingen voor een latent kwetsbaar zelfgevoel dat wil zeggen slecht tegen kritiek kunnen, alles zelf willen doen en maar doorzetten tegen beter weten in. Enerzijds kunnen deze eigenschappen leiden tot succes, maar bij voortdurende tegenslagen en onder invloed van langdurige stress en uitputting, kan deze afweer tekort schieten, waarna het kan komen tot gevoelloosheid en acting out. Hij raakt overspoeld door voor hem niet te hanteren gevoelens. Betrokkene is geneigd tè lang door te gaan waarbij hij zichzelf tenslotte niet meer kan bijsturen of hulp 
zoekt bij derden. Het is alsof het uit handen geven van een probleem bij hem leidt tot gevoelens van krenking, falen en onzekerheid. Hij gaat maar door en raakt ernstig depressief, waarbij de realiteit vertekend wordt beleefd en in een stemming van gevoelloosheid is het gekomen tot de brandstichting en later ook tot een suïcidepoging. In verband hiermee acht ik betrokkene verminderd toerekeningsvatbaar inzake het hem tenlastegelegde. De kans op recidive op korte termijn is vrijwel nihil, maar op lange termijn niet uitgesloten, omdat niet is te verwachten dat deze manier van in het leven staan spontaan zal verbeteren. Met het oog daarop is het van belang dat betrokkene in behandeling gaat, zodat hij zich in de toekomst beter leert begrenzen en zichzelf toestaat hulp van derden te accepteren.

\section{Gemeenschappelijke kenmerken}

Wat hebben deze drie voorbeelden nu gemeen? Ingrijpen door politie en justitie gebeurt als grensoverschrijding, bewust of minder bewust, heeft plaatsgevonden. Voor de diagnostiek is het een belangrijke vraag op welk niveau er geen begrenzing is geweest. Bij meneer $\mathrm{A}$. zien we repeterend criminogeen gedrag om aan geld te komen voor het gebruik van harddrugs, die op hun beurt leiden tot sterke realiteitsvertekening en gevoelsveranderingen en soms tot ernstige agressieve acting out. In zijn jeugd was hij ernstig verwaarloosd, maar hij was ook materieel verwend. Hij is op alle levensgebieden vastgelopen en vaak overgeleverd aan zijn impulsen. Tot uitstel van directe behoeftebevrediging is hij niet meer in staat. Hij is grenzeloos in zijn drugsgebruik en grenzeloos in zijn agressiviteit. Door zijn heftige agressie, de HIV-besmetting en de hepatitus-C, bestaat ook gevaar voor zijn omgeving en wordt hij om veiligheidsredenen aangemeld bij een landelijke afzonderingsafdeling. Bij meneer $\mathrm{B}$. zien we een psychiatrische ziekte met een duidelijke realiteitsstoornis. Hij projecteert zijn gedachten over homoseksualiteit en verkrachting op de buurman tegen wie hij zich meent te moeten beschermen. Betrokkene is overtuigd van zijn gelijk. Meneer C., die zijn zelfgebouwde huis in brand heeft gestoken, is tè lang alleen doorgegaan en was ook niet in staat zichzelf bij te sturen of hulp te zoeken bij derden. Ook bij hem kun je spreken van een begrenzingsprobleem. 


\section{Theoretische aspecten van de begrenzing}

Vanuit de ontwikkelingspsychologie weten we, dat een kind in de loop van de eerste levensjaren, nadat het voldoende gehecht is, autonomie kan ontwikkelen, met losmaking van vader en moeder. Zonder begrenzing kan geen individuatie plaatsvinden en ontstaat geen identiteit, geen eigenheid en geen gevoel van eigenwaarde. Als een kind opgroeit - met het idee dat alles kan en mag, - als het geen verschil weet tussen mijn en dijn en - als het geen onderscheid leert te maken tussen denken, voelen, willen en doen is later de kans op grensoverschrijdend gedrag aanzienlijk. Een kind dat overal zijn zin in krijgt, vindt dit ook later vanzelfsprekend en verwacht dat een ander altijd aan zijn verwachtingen voldoet. Pas als uitstel van bevrediging nodig is, kan er een innerlijke wereld ontstaan, gevuld met fantasieën en overbruggende gedachten. Naarmate we beter kunnen denken en fantaseren, hebben we meer vrijheid om in de geest te reizen, zodat we de behoefte aan directe wensvervulling kunnen overbruggen met fantasieën. Bij een beperkte intelligentie is echter het abstractieniveau in het denken laag en komt het eerder tot joyriding in een auto dan reizen in de geest. Als we in onze jeugd na een goede hechting optimaal worden gefrustreerd en we in staat zijn tot uitstel van directe behoeftebevrediging, groeit ons zelfvertrouwen en het gevoel van autonomie.

Dankzij onze motorische ontwikkeling krijgen we de mogelijkheid om fysiek afstand te nemen van de ander en dat geeft controle over nabijheid en afstand. Het kind komt erachter dat zijn lichaam grenzen en openingen heeft, die hij kan afsluiten. Door de lichamelijke mogelijkheid van sluiten en openen, ontstaat er een vergroot besef van Ik en niet Ik en dat helpt bij het separatieproces ten opzichte van de ouder en voor de verdere individuatie. Het verschil tussen ik en de ander wordt duidelijker. Bevestiging van die egogrenzen en respect voor het afgegrensde zelf zijn essentieel voor de verdere ontwikkeling. Incest en mishandeling kunnen leiden tot een gestoorde zelfbeleving en gestoorde afgrenzing van de ander, met gevaar voor slachtoffer-dader omkering in de toekomst. In het denken en voelen kunnen ook begrenzingstoornissen ontstaan in de zin van splitsing, isolatie van affect, loochening en ontkenning. Door deze breuken in het denken en voelen kunnen contacten leeg, betekenisloos en egocentrisch worden, totdat er zelfs geen verschil meer wordt gevoeld tussen levende wezens en dode materie. Alles wordt tot shit en de ander is nog slechts een magische wens- 
vervuller, die als vanzelfsprekend moet aanvoelen en zorgen, terwijl empathie voor die ander ontbreekt. Van hechting is dan geen sprake.

De laatste decennia is er veel aandacht besteed aan de neurobiologische en biochemische grondslag van onze psyche. Wanneer op het juiste moment geen interactie plaatsvindt tussen kind en omgeving, zoals bij allerlei vormen van verwaarlozing en mishandeling, dan kan dit leiden tot soms irreversibele neuronale circuits. De noodzaak om op de juiste momenten tot een goede afstemming van de neuronale circuits te komen en de moeilijke veranderbaarheid van eenmaal aangeleerde associaties, vormen de neurobiologische basis voor het belang dat psychoanalytici aan de kindertijd toekennen. Als er bij een psychische stoornis een aantoonbaar neurobiologisch substraat wordt gevonden betekent dit nog niet, dat verandering van dit substraat uitsluitend langs biochemische weg zou kunnen plaatsvinden. We weten dat omgevingfactoren en psychotherapie invloed kunnen hebben op een biochemisch evenwicht.

Wat wij meemaken en hoe wij bejegend worden is van invloed op hersenprocessen. Het is nog lang geen uitgemaakte zaak welke cerebrale veranderingen irreversibel zijn. Het is dus niet uitgesloten dat in de toekomst bijvoorbeeld psychopathie beter te beïnvloeden is, dan tot dusverre het geval is geweest. In de forensische psychiatrie zien wij regelmatig mensen die onvoldoende besef hebben van afgrenzing tussen zichzelf en de ander. De ander wordt beleefd als vanzelfsprekend verlengstuk van zichzelf. Mijn en dijn lopen door elkaar heen. In de relationele sfeer bestaan dan vaak onrealistische verwachtingen en sterke gevoelens van afhankelijkheid, afgewisseld door krampachtige losmaking met heftige ruzies en vlucht in gebruik van verdovende middelen, alcohol, sex of gokken, waardoor grenzen nog meer vervagen. Herhaalde niet te verdragen gevoelens van teleurstelling en woede kunnen dan leiden tot mishandeling of zelfs doding van de ander die weer niet voldoet aan de kinderlijke verwachtingen.

Soms wordt ook in de behandeling onderschat dat iemand nauwelijks een persoonlijkheid heeft ontwikkeld, laat staan dat hij beseft dat de ander er niet als vanzelfsprekend voor hem of voor haar is. Als voorbeeld noem ik een 24jarige jongeman D., die wegens meervoudige dodingsdelicten in een TBSkliniek verblijft. Hij leeft in de stellige overtuiging dat de ander wel aanvoelt wat hij nodig heeft en als hij niet krijgt wat hij wil, ervaart hij dit als pesten en treiteren, hetgeen leidt tot ernstige woede-uitbarstingen. In zijn jeugd zien 
we enerzijds sterke emotionele verwaarlozing met vele verlatingen en anderzijds minstens zo sterke verwenning met eten en andere materiële zaken. Ook deze man leeft in de overtuiging dat hij recht heeft op wat hij wil en de ander er is om hierin te voorzien. Alleen als behandelaars werkelijk besef hebben van dit begrenzingprobleem, zal blijken of er nog iets aan afgrenzing bij deze man kan ontstaan, dan wel dat permanente maatregelen nodig zijn ter beveiliging van zijn omgeving. Met begrip van dit diepgewortelde begrenzingsprobleem, zal men niet snel kiezen voor een assertiviteitstraining. Een belangrijke doelstelling in de behandeling bij forensische cliënten is het leren onderscheiden van denken, voelen, wensen, fantaseren en doen, maar ook leren dat er een verschil is tussen mijn en dijn.

\section{Beloop van een psychotherapie}

In het kort bespreek ik het beloop van een psychotherapie waarbij deze begrenzing een belangrijke rol heeft gespeeld.

Patiënte E. is bij aanvang van de ambulante therapie 40 jaar oud. De behandeling duurt tien jaar. Zij werd door de reclassering aangemeld, naar aanleiding van een poging doodslag. Ze had al eerder last van woede-uitbarstingen en ernstige depressieve buien. E. is opgegroeid als jongste in een gezin van negen kinderen. Moeder wordt door haar omschreven als dik, biddend en oververmoeid en door de pastoor ten voorbeeld gesteld aan de buitenwereld. Als jong kind moest zij het bed van moeder voorverwarmen en ze walgde van moeder, als deze tegen haar aan kwam liggen. Ze plaste in bed en voor straf moest ze met haar half opgedroogde kleren de volgende dag naar school en werd daar gepest omdat ze stonk. Er ontstond een gevoel van afkeer van zichzelf. Er werd bij haar thuis weinig gepraat en veel geschreeuwd. Moeder keurde vader af om zijn schuine moppen, maar hij voerde de boventoon. Hij kon het niet verdragen als de kinderen dingen niet in één keer begrepen. Patiënte werd op jonge leeftijd in een riviertje achter de boerderij gegooid, met het idee haar zo te leren zwemmen.

Er mocht niet worden geklaagd over het zware werk. Maar ze werd ook als een pop uit de kast gehaald als er bezoek kwam. Ze kreeg mooie kleertjes aan en werd gezoend door pastoor, ooms en tantes. Ook dit gaf weer een gevoel van walging. Een oudere zus was afgunstig op haar omdat patiënte als jongste vaders oogappel was en een beetje werd ontzien. 
Op de middelbare school doet een leraar aardig tegen haar, maar zij reageert met pesten en kleineren. Ze wil de verpleging in, maar is eigenlijk te jong. Haar moeder heeft een gesprek met de overste en zij adviseert moeder om haar dochter vooral hard aan te pakken. Patiënte praat vaak over de harde kanten van moeder. Ze kan zich herinneren dat ze bij moeder in de keuken zat en dat er biggetjes werden binnengebracht die met hetzelfde mesje waar moeder eerst de aardappels mee schilde, werden gecastreerd. De biggetjes gilden het uit van de pijn. Patiënte moest hier om huilen, maar werd daar om uitgelachen: je moest hard zijn. Tijdens de opleiding leert ze haar aanstaande man kennen. Ze omschrijft hem als een wat dwangmatige, rigide man, die zijn zin wil hebben. Zowel in de verpleging als in de relatie is het "erop of eronder". Als ze zich machteloos voelt, voelt ze bij zichzelf de neiging opkomen om patiënten te slaan, maar dan kan ze nog weglopen. Uiteindelijk loopt het huwelijk op de klippen. Hij verdraagt haar grilligheid niet en zij niet zijn starheid. Toch kunnen ze elkaar niet loslaten en tijdens een van die contacten volgt er een bijna steekpartij van haar kant en hij doet aangifte. Er volgt een voorwaardelijk sepot. Als bijzondere voorwaarde is opgelegd: toezicht door de reclassering en meewerken aan een ambulant psychotherapeutisch contact.

Bij de kennismaking zie ik een stevige vrouw met donker haar en een donkere, boze, uitdagende blik, die in de spreekkamer omslaat in diepe somberheid. Ze is inmiddels afgekeurd als lerares verpleegkunde in verband met wat dan heet overspannenheid. Ze neigt tot alcoholmisbruik en wil geen medicijnen, "want dan ben je zwak". Er is sprake van hechtingsproblematiek als gevolg van emotionele verwaarlozing in de vroege jeugd, met als gevolg separatie-individuatieproblematiek en een slecht ontwikkeld zelfgevoel. De afweerstructuur is primitief en bestaat uit projecteren, loochening en isoleren van het affect met als gevolg een slechte realiteitstoetsing alsmede affect- en impulsregulatieproblematiek. Verder is er een neiging tot boulemie.

Diagnostisch kan worden gesproken van een borderline persoonlijkheidsstructuur met begrenzingsproblemen op alle nivo's, namelijk. in het ego, de afweermechanismen, de affect- en impulsregulatie en in de relatiename. Gestart wordt met psychotherapeutische gesprekken on analytic lines, eerst eenmaal per week en na één jaar wordt dit tweemaal per week. Ze heeft een sterke behoefte in te willen halen wat ze heeft gemist. Ik, haar behandelaar, zou "haar alles moeten geven wat zij gemist heeft, want daar is een therapie toch voor?". Binnen de kortste keren is haar houding eisend en dwingend en 
probeert ze mij te provoceren. "Jij zit daar maar in die stoel, doe toch wat! Zorg er voor dat ik me beter voel, dit wil ik niet". Ze legt een enorme druk op mij, waarbij ik mij verre van comfortabel voel. Steeds benoem ik haar kinderlijke deel, dat wil hebben en krijgen, en aan haar meer volwassen deel vraag ik, wat er in haar ontbreekt, dat ze niet goed voor zichzelf zorgt en dat ze de verantwoordelijkheid om zich goed te voelen bij mij legt. Ze wordt razend en loopt midden in het uur kwaad weg. Ze smijt met deuren en laat mij in spanning achter. Later belt ze op of ze nog kan komen. Ze vertelt dat ze de neiging had het stuur los te laten, maar het niet heeft gedaan. Ze praat dan over de herinnering, dat haar vader met zijn auto is verongelukt toen zij twaalf jaar was. Het was enerzijds een opluchting dat hij er niet meer was, maar ze miste toch ook zijn activiteit en geestdrift. Bovendien was ze daarna helemaal overgeleverd aan haar moeder. Na drie jaar therapie verongelukt haar oudste broer, ook in een auto en op dezelfde datum als haar vader, jaren daarvoor. Terstond speelt zij met de gedachte aan suïcide, waarbij ik telkens de grens benoem tussen haarzelf en de ander, maar ook tussen haar denken, wensen, gevoelens, ideeën en daden. Door voortdurend het onderscheid te benoemen, ontstaat er iets meer rust. Ze was vroeger niet gewend aan enige ruimte tussen voelen en doen. Ze was overgeleverd aan vaders driftbuien en hij gaf het voorbeeld van direct doen. "Niet zeuren, maar doen".

In een eerdere therapie heeft ze geleerd vooral haar gevoel te volgen, maar wat als die gevoelens leiden tot je eigen ondergang. Ze begint te beseffen dat ze nooit geleerd heeft om iets uit te stellen, iets niet te doen. Sterker nog, als je wou meetellen moest je doen en niet aarzelen. Juist over grenzen gaan, direct terugslaan, in het water springen. Als je moe bent, juist doorfietsen. Als je hoogtevrees hebt, juist de berg op. Je zou kunnen spreken van een contrafobische levensstijl met sadomasochistische neigingen, in ieder geval werd zachtheid belachelijk gemaakt. Maar ook voor gevoelens van teleurstelling of verdriet was geen ruimte. Door dit telkens te benoemen, en te benoemen dat ze mij telkens moet laten voelen hoe het is om vernederd te worden, belachelijk gemaakt te worden, begint er bij haar iets te dagen. Maar mijn aandacht wordt verdacht gemaakt, belachelijk gemaakt, onderuit gehaald en ze wil me opjuinen tot actie. Ze kleineert mij en laat mij vaak in verwarring achter of kijkt alleen boos en stapt aan het eind van het uur zonder meer op. Het is testing the limits. Ze projecteert voortdurend haar gedachten. Ze zegt bijvoorbeeld dat ik wil dat zij zich doodrijdt. Telkens moet ze onderuit halen wat wij hebben opgebouwd: dat kan ze heel goed. Maar ik zeg haar ook dat ik het pas echt knap zou vinden als zij iets heel kan 
laten, als zij mij heel kan laten en dat zij zichzelf heel laat. Ik beaam dat ik het een zware therapie vind, maar ik zeg ook, dat ik de hoop heb dat zij haar verstandig denken en energie beter gaat gebruiken.

Geleidelijk aan ontstaat er meer hechting, met daaraan gekoppeld een besef van existentiële eenzaamheid. Dat laatste is niet erg en het hoort bij de volwassen wording en ze leert dit af te grenzen van de depressie, maar in het begin lokt het één vaak het ander uit. Bij onderbrekingen ervaart ze voor het eerst het gevoel van gemis en zij begint zelf met het sturen van kaartjes in haar vakanties. Ze moest eerst alles stuk maken van wat we hadden opgebouwd, nu blijft er een gevoel van contact bestaan. Op een gegeven moment gaat ze op therapeutische basis aan het werk. Met haar temperament wekt ze de indruk veel te kunnen en binnen de kortste keren neemt ze te veel verantwoordelijkheid op zich. Ze oogst daarmee waardering van de directeur van haar school. Een paar keer gaat ze over haar grenzen, maar nu voelt ze wat er gebeurt. Ze schakelt namelijk haar gevoel uit, raakt oververmoeid, prikkelbaar en vindt nergens meer wat aan.

Nog steeds koestert ze de hoop, dat ze de favoriet wordt van haar leidinggevende en dat hij precies weet wat goed voor haar is, dan wel dat ik daar voor zorg. Toch begint ze te beseffen dat ze lang kan wachten en dan ontstaat weer dat gevoel van existentiële eenzaamheid, maar ook van het kind dat verder wil, door vertrouwen op iets in zichzelf en ze onderneemt allerlei activiteiten. Ze leert zwemmen, kanoën, salsadansen en koopt een caravan. Ze kan de deur openzetten als zij dat wil en dichtdoen of wegrijden als het haar niet bevalt. Ze gebruikt haar energie op een gezondere manier, heeft meer regie over haar leven. Ze hoeft niet meer toe te geven aan al haar gevoelens en gebruikt meer haar verstand. En ze begint er lol in te krijgen, dat niet alles in een keer goed kan zijn en dat je mag oefenen en spelen. In het zicht van het afsluiten van de therapie lijkt het of het hele bouwwerk weer in elkaar stort. Ze zegt zich verschrikkelijk in de steek gelaten te voelen, maar uiteindelijk overwint haar wens naar onafhankelijkheid en autonomie. Ze beseft dat ze veel heeft gemist wat niet meer is in te halen, maar ze weet ook dat ze zich beter kan afgrenzen in relaties en beter grenzen kan stellen aan opkomende gevoelens van woede en teleurstelling. 


\section{Conclusie}

Bij een delict is er duidelijk iets misgegaan met de begrenzing tussen mijn en dijn. Of het nu gaat om diefstal, moord, incest of doding ten gevolge van rijden onder invloed, steeds weer betreft het een grensoverschrijding, waarbij ook het leven of welzijn van een ander in het geding zijn geraakt. Ik wil er voor pleiten om in onze diagnostiek oog te hebben voor de aard van begrenzingproblemen en die trachten te doorgronden en daar in de behandeling rekening mee te houden. In plaats van terugkeer naar een paradijs vol illusies kan besef van de gewone werkelijkheid ontstaan met de mogelijkheid van een rijker geschakeerd gevoelsleven waarbij een ander het niet hoeft te ontgelden.

\section{Literatuur}

- Bion W.R. (1962), A theory of thinking Second Thougts (1976), William Heinemann Medical Books Ltd.

- Boer F. (2009), Stress in het begin van de levensloop; een ontwikkelingsperspectief, in: Tijdschrift voor psychiatrie, 2009/8, 579-587

- Bonaparte M. (1967) Sexualité de la femme, Paris, UEG, coll. $<<10 / 18>>$

- Campbell D. (1999), The role of the father in presuicide states in Perelberg R. (1999), Psychoanalytic understanding of violence and suicide Routledge

- Cardinal M. (1975), Les mots pour le dire, Paris, Grasset

- Eagleton T. (2005), Tragedy and terrorism in Bulletin of the British psychoanalytic Society, Vol.41 No.7

- Fonegy P. and Target M. (1999), Towards understanding violence: the use of the body and the role of the father, in: Perelberg R. (1999), Psychoanalytic understanding of violence and suicide Routledge

- Freud S. (1923), The infantile genital organization SE Vol.VIII

- Glasser M. (1996), Agression and sadism in the perversions, Oxford University Press

- Hinshelwood R.D. (1989), A dictionary of Kleinian Thought, Free Association Books

- Horney K (1922), La psychology des femmes, trad.G.Rintzler, Paris, Payot, 1969

- Klein M. (1958), On the development of mental functioning 
- Laplanche J. et Pontalis J.B. (1967), Vocabulaire de la psychoanalyse, Paris, PUF

- Laufer M. and Laufer M.E., (1984), Adolescence and developmental breakdown-A psychoanalytic view New Haven CT, Yale University Press

- Nicolai N.J. (2009), Chronische stress, sekse en gender in Tijdschrift voor Psychiatrie, 2009/8, 569-579

- Perelberg R. et al. (ed), (1999), psychoanalytic understanding of violence and suicide Routeledge

- Shengold L. (1989), Soul murder: the effects of childhood abuse and deprivation, Yale University

- Sohn L., Unproveked assaults- making sense of apparently random violence, International Journal of psychoanalysis, 76, 565-575

- Steiner J. (1993), Psychic retreats-Pathological organisations in psychotic, neurotic and borderline patients, London, Routeledge

- Winnicott D.W. (1988), Human Nature, Christopher Bollas, Madeleine Davis \& Ray Shepherd, editors. London, Free Association Books

- Winnicott D.W. (1963), Communicating and not communicating leading to a study of certain opposites, in: Maturational Processes and the facilitating environment, Hogarth Press

- Winnicott D.W. (1969), The use of an object and relating through identifications, in: International Journal of psychoanalysis, 50, 711-6. 